\title{
Specific Application of Cross-cultural Context in College English Teaching
}

\author{
Du Yanfei \\ Department of Foreign Languages Teaching, Baicheng Normal University, Baicheng, 137000, China
}

Email: 545980720@qq.com

Keywords: Cross-Cultural Context, College English, Teaching

\begin{abstract}
Language and culture are inextricably linked. In the new historical period, the pace of economic globalization has been quickened, and multicultural exchanges have become increasingly frequent. The paper also began to highlight the cross-cultural barriers caused by cultural differences. As an important language in language learning, college English teaching is the milestone of English teaching. In the process of teaching, cross-cultural context plays a more and more important role in the whole teaching mode. In order to better transform into applied undergraduate teaching, it is necessary for the educators concerned in college English teaching to have a good understanding of cross-cultural context, so as to take advantage of its characteristics and advantages. Combining with the present teaching situation and the own characteristics of students, more flexible college English teaching can be carried out in order to carry out the quality education, the comprehensive ability of English of college students can be improved steadily, and students can become the talents who meet the needs of social development. The paper focuses on college English teaching in cross-cultural context, hoping to provide some reference value for college English teachers.
\end{abstract}

\section{Introduction}

With the development of quality-oriented education, the lecturing English teaching of traditional teaching English has obviously been unfavorable to the development of the times. The process of globalization is speeding up, the world is in the stage of pluralistic development, and the degree of mutual penetration and integration of cultures between countries is getting deeper and deeper. As an important subject in cross-cultural teaching, English teaching is constantly being optimized and improved. Due to the existence of objective factors such as the cultural differences between the East and the West, the study of understanding and attaching importance to the cultural background knowledge has been praised by more and more teachers [1]. The use of cross-cultural context for oral expression, English writing and other teaching practices will help students learn something, learn to use, and improve the accuracy of English language skills. First of all, we should have a basic understanding of cross-cultural context, and then explore the basic role of cross-cultural context in college English teaching, and then combine the current situation of teaching development. This paper analyzes the application of college English teaching in cross-cultural context to promote the improvement of college English teaching results.

\section{A Brief Account of Cross-Cultural Context}

In the communication between people, involving the cultural phenomena, customs, habits and other specific knowledge backgrounds resulting from the ideological differences formed by a certain nationality, we have gained a deeper understanding and cognition through the way of language communication. On this basis, it accepts and adapts gradually with an inclusive attitude, and thus comes the cross-cultural context. Language is the carrier of culture, so the promotion of cross-cultural context is mainly in the field of foreign language teaching. College English teaching, in the traditional teaching class, mainly to teach both hands English words, grammar and other theoretical knowledge. In recent years, with the establishment and consolidation of cross-cultural awareness, the study of cross-cultural context has been gradually deepened. Under this background, college English teaching has begun to attach importance to the study of cultural background and 
cultural psychology. It is embodied in the cultural custom, ideology, era characteristic and so on, which are expressed in the process of communication through cross-cultural context. The organic combination of English culture and English language skills improves the quality of college English teaching to some extent [2].

\section{The Role of Cross-Cultural Context in College English Teachings}

English as a foreign language, cultural introduction is a major feature of educators engaged in English teaching, therefore, in higher education, to deepen the understanding of the cultural background of English-speaking countries, students can improve the practical application of English knowledge more quickly and reduce the cross-cultural barriers or conflicts caused by cultural differences. With the analysis and deepening of cross-cultural context by educators, cross-cultural context plays an important role in the application of college English education.

First of all, in language teaching, the transmission of culture has two sides of positive and negative. For example, in both native Chinese and English-speaking countries, people say "XieXie" or "Thank you" when they express their gratitude, in essence, "XieXie" and "Thank you" actually express gratitude for the kindness of others, which is a positive transfer of culture. Conversely, the negative transmission will also exist. For example, because of the cultural differences between the East and the West, when Chinese people say "goodbye" when they say goodbye to their guests, they will also say "go slowly" because of the traditional way of hospitality, but in Western countries, "Goodbye" does not add after the habit of communication, the Chinese expression of the habit of "walk slowly" here is not suitable to resonate. Obviously, cross-cultural context has a certain restriction on spoken English in English teaching [3].

Secondly, combining with the past experience in English learning, there is a great difference between spoken English expression and written expression. Written expression stresses the correctness and logic of grammar, but the requirements of oral expression are relatively loose. In many cases, people are restricted by objective conditions and their own ability in the process of communication, they often pay attention to let the other side realize the basic content to express, but in the process, they often do not emphasize whether the grammar is accurate or not. In the process of adapting to cross-cultural context, teachers should guide students to distinguish between written and oral expressions. Through the influence of the cultural background, it is easier for the students to form the corresponding expression habits and expressions suitable for their own characteristics, which is helpful for the students to exercise their oral English ability.

At the same time, as far as written English expression is concerned, in the context of cross-cultural context, students learn about different cultures, customs and conditions related to English learning by absorbing and enriching cultural background knowledge. If things go on like this, students will understand and remember more quickly when he studies written English texts. For example, in the application letter expressed in Chinese, we usually use the method of cutting directly into the subject, and state the reasons for the application in the first place. However, in cross-cultural context, the expression is completely opposite in terms of English reading habits. And so on, because of the contrast of cultural differences, if we directly use Chinese expression habits in English expression, or reverse try, it is not suitable to understand the meaning of it. In the organic combination of cultural background and English knowledge, cross-cultural context plays an important role in interpreting written language [4].

\section{The Present Situation of College English Teaching Development in Cross-Cultural Context}

According to the relevant data, there are still some problems in the process of college English learning, such as insufficient understanding of foreign books, and lack of confidence and shame over speaking due to psychological factors. In the teaching of college English, the evaluation system is still in written form, which leads students to stay at the level of formal English.

On the one hand, under the influence of traditional exam-oriented education, English grammar, word-formation, translation and other knowledge teaching still occupy more space in the process of 
English teaching, and classroom teaching lacks the opportunity to guide students to analyze their cultural background, which is the main reason that hinders college English teaching level. In the case of Copycat, why use cat to mean "plagiarism"? Back in 1887, in the American Civil War, the days of Port Barr, there was a saying, "Our boys say you are a copy cat,if you write in anything that's been already printed." In terms of social reality at the time, most people thought that cats were an unpredictable creature, and that they happened to be nocturnal animals, not often exposed to the sun, so they associated themselves with the bad behavior of not seeing light. The author described the plagiarists with this image, which was used in the future. It is obvious that even an English word has a profound meaning behind it [5]. However, in college English teaching, teachers often follow the order of words, sentences, paragraphs and articles. The teaching arrangements that refine the meaning of words to the origin of word interpretation are not considered in terms of teaching schedule requirements and teaching time limits, which makes the students in English learning foundation is not solid enough.

On the other hand, there is a lack of cultural orientation in college English teaching. College English learning is under the pressure of CET-4, CET-6 and even IELTS. Although the oral skills test has gradually been incorporated into the examination system, the overall standard for measuring the results is still mainly volume inspection, which has also a higher demand for knowledge of English. In this teaching environment, for the sake of students' achievement and assessment of teaching, teachers still focus on teaching in the classroom teaching, and the students have insufficient access to the English cultural field. There are few attempts to practice cross-cultural communication. Students can not deeply understand the culture behind English knowledge, and it is even more difficult to communicate deeply in the social environment in the future. At present, with the development of quality education reform, a series of reform attempts made by the Ministry of Education for college English have shown that it is urgent to cultivate cross-cultural communication ability of students. In order to ensure the quality and level of English teaching, we can scientifically formulate the implementing strategies of college English teaching in cross-cultural context.

\section{Practical Strategies of College English Teaching in Cross-Cultural Context}

There is no doubt that cross-cultural context directly affects the effect of college English teaching, and the construction of a new model of college English teaching in cross-cultural context is suitable for the overall development of college English teaching in China. In order to ensure the quality of college English teaching, the teaching staff should follow a reasonable path. As the source of English knowledge point, English culture should run through the whole activity of English teaching and realize the equal emphasis of knowledge and culture, which is the focal point of college English teaching at present [6]. Based on this, we can carry out practical strategies of college English teaching in cross-cultural context from the following aspects.

\subsection{Deepening the Details and Improving the Teaching Methods of Each Knowledge Point.}

As the most basic element of English, a good foundation is half of success. With the advantage of intelligent electronic products, starting with words, teaching with multimedia courseware and integrating sound and painting, the teaching includes the reading, writing and interpretation of words, and it is necessary to understand the origin of the formation of this word to understand the inherent meaning of the word. Take a simple month as an example, the nouns of January to December in English have evolved from quite wonderful stories in Western culture, such as August: Octavian, the first emperor of the ancient Roman Empire, was awarded the veneration of Augustus by the Roman Senate in August, and Octavian decided to name it August. As far as the study of a word is concerned, it is better to recognize the famous historical figures in western culture and to guide students to explore the basic process of the Roman Empire. From words to sentences, forming paragraphs, finally forming articles, details as the lead, on the one hand, that can expand the knowledge of students of English culture, on the other hand, interesting and vivid ancient Greek and Roman mythology is one of the important sources of English culture, its winning plot and understanding can enhance undefined interest of students in learning. For the teachers themselves, 
the innovative teaching method itself is an effective measure to improve the teaching quality, break through the shackles of the teaching class, mobilize the enthusiasm of students, through the humanistic story also enriched the feelings of students and promoted the humanistic literacy.

\subsection{Deepening the Consciousness of Intercultural Communication and Strengthening the Integration of Native Culture in Teaching Practice.}

The immediate goal of college learning is to enable students to better integrate into the workplace, serve society, and not be buried by the times. cross-cultural context is not only to combine English learning with English cultural background, but also to strengthen the relationship with the reality of life, and combine with local culture to improve their English practice ability[7]. With the deepening of the new curriculum reform, the content of Chinese culture has also increased in the compilation of college English textbooks. Excellent culture is supposed to have the strength of a hundred schools, We Media is developing at a high speed, students should be guided to read and understand bilingual works in Chinese and English, such as China Daily Bilingual News, with the help of excellent self-media products such as public articles and articles. By combining the facts of life with the knowledge of English, the students have strengthened the memory of English words and grammar besides leisure, accumulated many kinds of cultural materials, and realized the important position of Chinese culture in globalization. To some extent, it promotes students to improve their comprehensive language competence in cross-cultural context.

\section{Conclusion}

To sum up, college English teaching in cross-cultural context is a new mode of creative culture teaching, which is constructed consciously in the process of teaching. When English teaching goes deep into ideology, understanding of cultural customs and characteristics of the times for college students to go out of the classroom to enter the society, and even go abroad to the world has a considerable positive role. The reform of quality-oriented education makes the teaching work of university educators more flexible, and the construction of college English model in cross-cultural context is a dynamic process. It is very necessary for colleges English teachers to construct and increase the application of cross-cultural context teaching mode in college English teaching system, to enrich the educational content in four aspects: listening, speaking, reading and writing, and to improve the comprehensive English ability of students, so as to provide high-quality education personnel for social development.

\section{Acknowledgements}

In this paper, the research was sponsored by the Educational Science Project of Jilin province during“13th Five-Year Plan”in 2018(No. GH180588).

\section{References}

[1] WANG Weitong. The cultivation of Intercultural communicative competence in College English Teaching [J].Heilongjiang Science, 2018,9(19):110-111.

[2] WANG Lishou. Cultural context differences and their implications for College English Humanities Education [J].Journal of Changchun Normal University, 2018, 37(09):172-174.

[3] MA Hedan. The Construction of College English Teaching Model based on Intercultural Communication [J].Cultural and Educational Materials, 2018(26):199-200.

[4] MING Ming. Cultivation of College English Intercultural communicative competence and Reconstruction of Evaluation system [J]. Journal of Shandong Agriculture and Engineering University, 2018,35(08):175-176.

[5] SHI Yuting. The cultivation of Intercultural communicative competence and the practice of 
College English Teaching [J]. Journal of Puer University, 2017,33(06):109-110.

[6] LIU Jiao.A study on the Strategies of cultivating Intercultural communicative competence in College English Education [J]. Science \& Technology Vision, 2017(36):46+32.

[7] JI Shaofeng. The Application of Cultural context in College English Teaching [J]. Ability and Wisdom, 2017(03):124. 